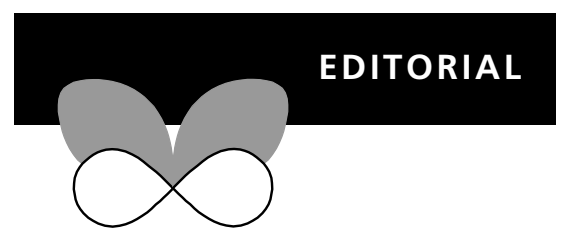

\title{
Fifty years of invasion ecology - the legacy of Charles Elton
}

\author{
David M. Richardson ${ }^{1 \star}$ and Petr Pyšek ${ }^{2}$
}

${ }^{1}$ Centre for Invasion Biology, Department of Botany and Zoology, Stellenbosch University, Matieland 7602, South Africa,

${ }^{2}$ Institute of Botany, Academy of Sciences of the Czech Republic, CZ-252 43 Průhonice, Czech Republic, and Department of Ecology, Charles University, Viničná 7, CZ-128 01 Praha 2, Czech Republic

${ }^{*}$ Correspondence: David Richardson, Centre for Invasion Biology, Department of Botany and Zoology, Stellenbosch University, Private Bag X1, Matieland 7602, South Africa.

E-mail: rich@sun.ac.za

\begin{abstract}
The publication, in 1958, of Charles Elton's book The ecology of invasions by animals and plants launched the systematic study of biological invasions. Invasion ecology has grown to become an important multi-disciplinary subfield of ecology with growing links to many other disciplines. This paper examines the citation history of Elton's book using the Web of Science. We also examine Elton's influence in shaping the current research agenda in invasion ecology, for which we use the 28 papers in a special issue of Diversity and Distributions (Volume 14:2) as a representative sample.

After 50 years, Elton's book remains the most cited single source in the field ( $>1500$ citations), and is cited more often every year ( $>100$ times) than any other invasion-related publication, including influential papers in journals. Most citations to Elton's book refer to particular topics/concepts covered in the book, rather than citing it as a general reference about invasions. The shift in the distribution of topics/concepts cited with reference to Elton over time follows the same trend as for biogeography and ecology in general (increasing emphasis on analytical studies, multi-scale analyses, multi-disciplinary studies, etc.).

Some topics emphasized by Elton are still the focus of current research (dispersal and spread of invasive organisms, impact on biodiversity, role of disturbance and enemy release) but several prominent themes in modern studies were not addressed by Elton. The emergence of new themes can be attributed to a general change in approach and emphasis underpinning research questions in conservation biogeography and applied ecology over the last half century (risk analysis, multi-scale comparisons, propagule pressure, experimental approaches) and to the recent emergence and increasing availability of large data sets on the distribution of introduced species and to the emergence of key technologies (e.g. geographic information systems, modelling techniques, including niche-based modelling, and molecular methods). Half a century after its publication, Charles Elton's book on invasions remains influential, but massive changes in the status of invasions and other environmental issues worldwide, together with advances in technology, are reshaping the game rules and priorities of invasion ecology.
\end{abstract}

\section{Keywords}

Bibliometric analysis, biological invasions, citation analysis, data availability, invasion ecology, methodological tools, research topics.

\section{INTRODUCTION}

Invasion ecology is the study of the human-mediated introduction of organisms, especially introductions to areas outside the potential range of given organisms as defined by their natural dispersal mechanisms and biogeographical barriers (Davis, 2006; Mack et al., 2000; Richardson \& Pyšek, 2006). The field addresses all aspects relating to the introduction of organisms, their ability to establish, naturalize and invade in the target region, their interactions with resident organisms in their new location, and the consideration of costs and benefits of their presence and abundance with reference to human value systems (Richardson \& van Wilgen, 2004; Pyšek et al., 2006; Richardson, 2006).

Several 19th century naturalists, notably Charles Darwin, Alphonse De Candolle, Joseph Hooker and Charles Lyell, mentioned invasive species in their writings. Naturalized and invasive species were, however, essentially curiosities at the time and were not perceived as a major threat to global biodiversity. 


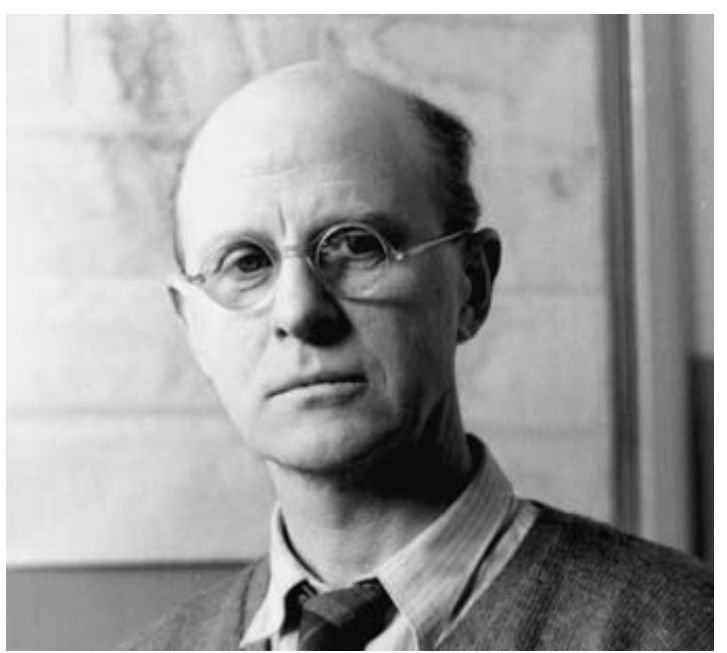

Figure 1 Charles Sutherland Elton (1900-1991). His book The ecology of invasions by animals and plants is widely acknowledged as launching the systematic study of biological invasions. Photo courtesy of the Department of Zoology, University of Oxford.

Biological invasions started becoming much more widespread in the first half of the 1900s, but biologists were slow to focus attention on the phenomenon (Richardson \& Pyšek, 2007). Charles S. Elton's (1958) book on The ecology of invasions by animals and plants is generally acknowledged as the starting point for focussed scientific attention on biological invasions (Fig. 1).

Invasion ecology has grown enormously in the 50 years since Elton's volume appeared (Pyšek et al., 2006; Richardson \& Pyšek, 2007). The book has been very widely cited, and has been discussed in several publications describing aspects of the growth of invasion ecology (Cadotte, 2006; Davis, 2006; Richardson \& Pyšek, 2007). However, we know of no focussed analysis of how Elton's book has been cited on which to base an assessment of its role in guiding research in the field. Neither is it known whether there have been clear changes over time in the way the book has been cited, and how much current research on invasions still draws insights from the book.

This paper reports on a bibliometric analysis of the citation history of The ecology of invasions by animals and plants. We also draw on the collection of papers assembled in a special issue of Diversity and Distributions (Volume 14:2), taking this as a reasonably representative sample of the topics (other than purely management-focussed studies which are not covered in this journal) that are currently enjoying research attention in invasion ecology, to discuss major advances and innovations since Elton's time that are driving the current research agenda on this topic.

\section{METHODS}

For a sample of the literature on biological invasions we used the following terms and their combinations for a search of the Web of Science ${ }^{\circledR}$ (WoS; accessed 18 May 2007): (biological) invas* (species); plant; animal; bird; mammal; insect. This yielded 3752 papers (Fig. 2) that were cited 45,342 times. Citations to the book of Elton (1958) were extracted from WoS on the same date.

To determine which ideas and concepts mentioned in Elton's book are actually cited and to see whether there have been clear trends and shifts in focus over time, we randomly selected 20 papers from each decade (1960s, 1970s, 1980s, 1990s, 2001-2006) from those citing Elton's book (Web of Science, accessed 18 May 2007) (see Supplementary Material, Appendix S1). References to Elton's book in each paper were grouped as follows:

(A) Descriptive issues included references to (1) invasions in general; (2) population dynamics of invaders, rate of growth and predator-prey relationships; (3) range expansions, population outbreaks and 'ecological explosions'; (4) dispersal, spread and elimination of barriers; (5) impact of invasions on community diversity and structure; and (6) references to particular species as examples of successful invasions.

(B) References to patterns of invasion included (7) the diversityinvasibility relationship (biotic resistance); (8) invasibility of islands; and (9) stability (diversity-stability relationship, community saturation, landscape stability).

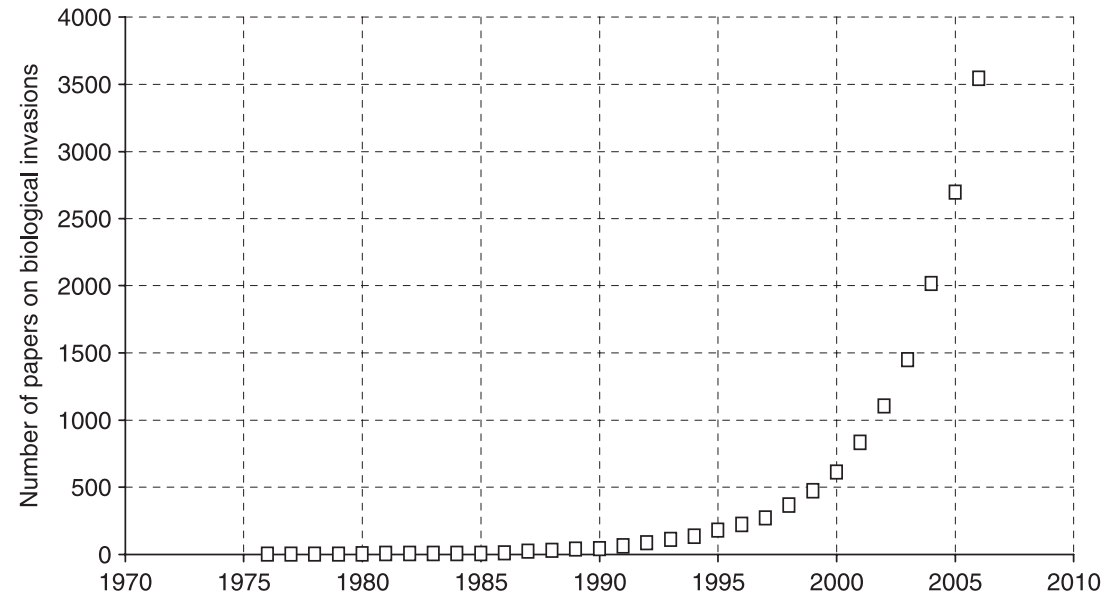

Figure 2 Growth in the number of papers in invasion ecology published up to 2006 and registered on the Web of Science (see text for the methods of screening for relevant papers). 
Figure 3 Cumulative number and annual number of citations of Elton's (1958) book The ecology of invasions by animals and plants between 1960 and 2006.

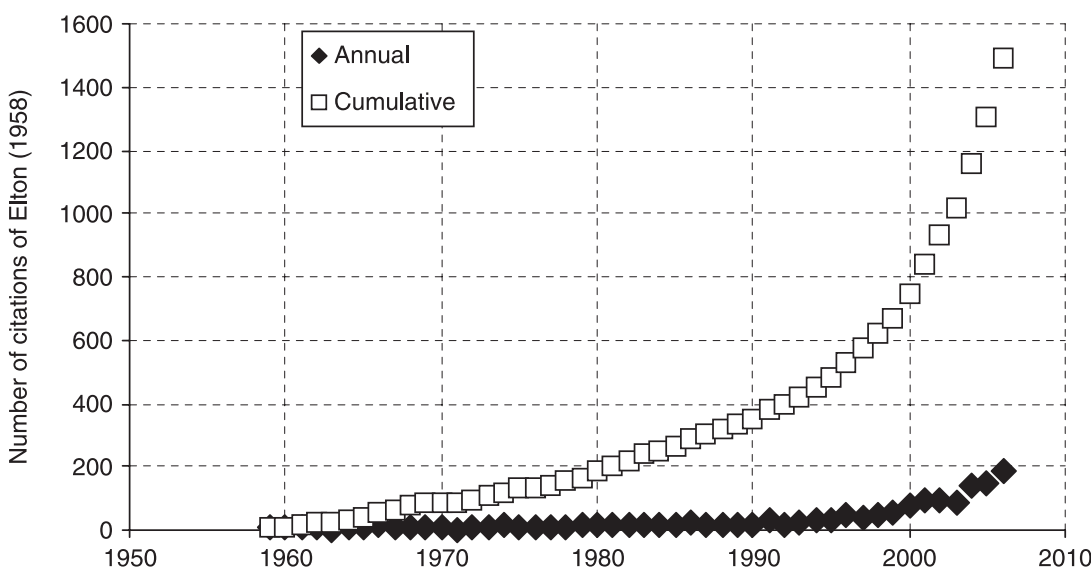

(C) References related to mechanisms of invasion included (10) enemy release; (11) the role of disturbance; (12) resource utilization and niche partitioning (empty niche); (13) competition and competitive displacement; and (14) climate matching.

In addition, there were single references to biological control and palaeoecology.

\section{RESULTS AND DISCUSSION}

\section{Elton's book as the most cited source in invasion biology}

There were, up to 18 May 2007, a total of 1516 citations of Elton's book, with an exponential increase in citations starting in the mid-1990s. Until then, the book was cited fairly steadily, with a linear increase of citations over time (Fig. 3). This makes Elton's book the most cited source in invasion biology, as can be inferred from comparison with the numbers of citations of the most highly cited papers on biological invasions in journals (Mack et al., 2000; D'Antonio \& Vitousek, 1992; Carlton \& Geller, 1993), with maximum numbers of the most cited papers not exceeding 500 (WoS, accessed 8 August 2006, see Pyšek et al., 2006 for details). The book is still widely cited, as indicated by 185 citations in 2006, 149 in 2005 and 137 in 2004.

Using the average number of citations per year as a measure for comparing Elton's book with the most cited papers in journals, yields 31.0 citation per year for Elton, which is lower than the highest values found for the paper (six papers received on average more than 50 citations per year, see Pyšek et al., 2006). However, in fairness we need to compare the number of citations to Elton's book for the recent period since numbers of citation have been increasing steadily. For 2000-2005, i.e. the period over which most of the journal papers mentioned above have accumulated their citations (reported in Pyšek et al., 2006), there were on average 105.7 citations to Elton's book every year, which exceeds even the per-year citation rate of the most highly cited paper (Mack et al., 2000 - 89.6).

The first paper recorded on Web of Science with obvious relevance to biological invasions was from 1976. It should be noted that there are several earlier papers dealing with invasive species that were not picked up in our search because they did not include relevant keywords. Such papers are too few in number to have much influence on the dynamics reported on here. The number of papers first increased slowly, and then exponentially from the mid-1990s (Fig. 2). Why was there such a long lag phase between the publication of Elton's book and the first papers that explicitly dealt with biological invasions? This could be because studies dealing with invasions published between 1960 and 1980 did not consider alien organisms sufficiently important to mention explicitly in titles, keywords, or abstracts. The awareness of the importance of the phenomenon changed markedly with the launch of the SCOPE programme on biological invasion in the mid-1980s, which initiated intensive research in many parts of the world (Drake et al., 1989; Richardson \& Pyšek, 2007). Also, invasions were not nearly as widespread as they are now during this lag period, so received less attention. This underscores the visionary nature and sharp observational skills of Charles Elton in recognizing the emerging importance of biological invasions decades before his followers.

\section{How is the book cited?}

\section{Main topics}

Diversity-stability and diversity-invasibility relationships are the topics for which Elton's book has been most widely cited in the scientific literature (Richardson \& Pyšek, 2007); these topics together account for a third of all citations to the book. Surprisingly, the book is rarely cited as a general reference for the problems associated with invasions. This indicates that it is cited primarily for fundamental concepts and viewed as a source of ideas. Other widely cited topics (accounting for $>5 \%$ of total) from Elton's work relate to invasibility of islands, enemy release and competition as mechanisms of invasions (Fig. 4). Charles Elton clearly launched the systematic study of biological invasions. He was a visionary scientist who fostered considerable cross-disciplinary synergy; this view is shared by most prominent researchers in the field (Richardson \& Pyšek, 2007). 


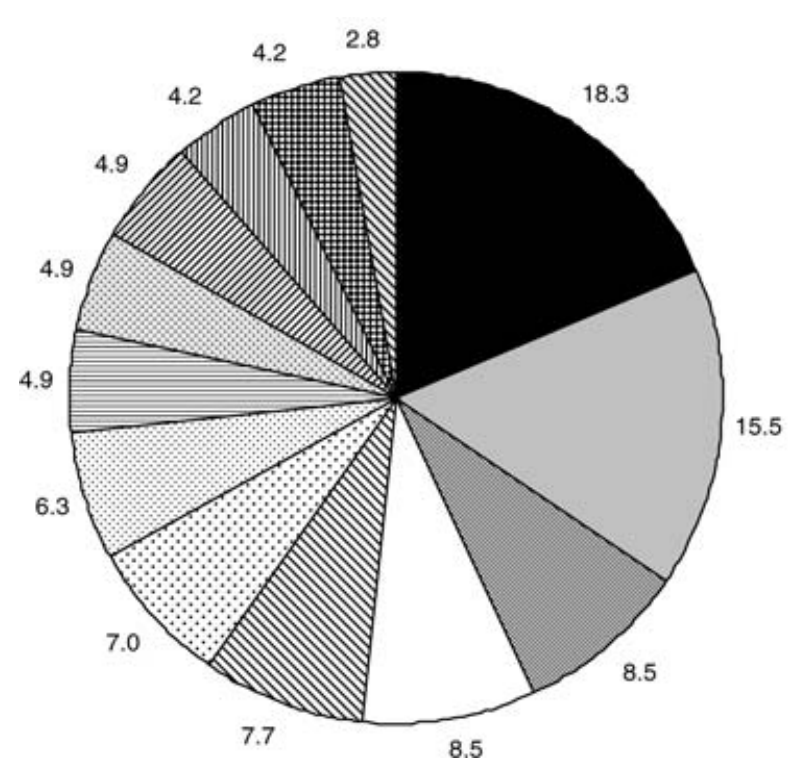

Stability (B)

$\square$ Diversity-invasibility (B)

$\square$ Invasions general (A)

口Islands (B)

ब Impact (A)

[. Enemy release (C)

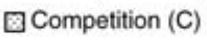

目Dispersal (A)

중 Resources (C)

Species examples (A)

II Range expansions (A)

\# Disturbance (C)

$\triangle$ Population dynamics (A)
Figure 4 The distribution of topics dealt with in Charles Elton's (1958) book The ecology of invasions by animals and plants as referred to in 100 randomly selected papers published between 1960 and 2007 (see text for details). Values are percentage of the total number of topics referred to. Some papers referred to more than one topic hence the total number of 142 individual cited topics referred to $(=100 \%)$ is higher than the number of papers. Numbers refer to broad issues explained in text: $\mathrm{A}$ - descriptive, $\mathrm{B}$ - patterns of invasions, and $\mathrm{C}-$ mechanisms of invasions.

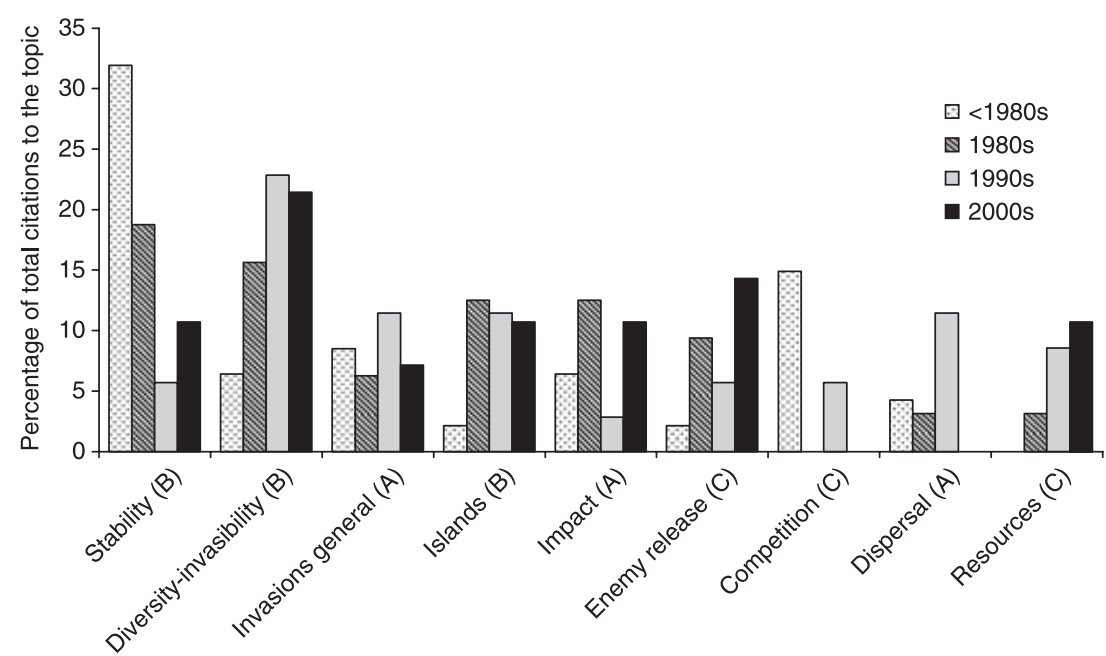

Figure 5 Changes in citation focus in papers referring to Charles Elton's (1958) book The ecology of invasions by animals and plants over 47 years (1960-2007). The period of two decades (1960s-1970s; shown as ' $<1980$ s') before invasion biology started to be recognized as a discrete field of study (see text) is merged. Only the most frequently cited topics are shown. Numbers associated with topic names refer to broad issues explained in text: A - descriptive, $\mathrm{B}$ - patterns of invasions, $\mathrm{C}-$ mechanisms of invasions.

\section{Changes over time}

References to particular topics in Elton's book show clear temporal trends (Fig. 5), reflecting shifts in focus in ecological disciplines. Invasions started to be recognized by the scientific community as a discrete field of study at the beginning of 1980s. Until then, most references to Elton's work relate to diversity-stability relationships and competitive interactions (not necessarily associated with invasions of alien species), i.e. general ecological issues intensively studied in 1960s and 1970s. These issues decreased in importance, although the former morphed into the consideration of the effect of stability, via diversity, on invasibility (Richardson \& Pyšek, 2007). The 1980s saw a shift in focus to themes with clear invasion relevance, such as the diversity-invasibility relationship, which steadily increased in relative importance in the following two decades. Basically, all important issues that are covered by the book and which are still the focus of research today were recognized as early as the 1980s. Besides the diversity-invasibility relationship, there are three more topics, i.e. enemy release, dispersal-related issues and resources, for which citation of Elton is increasing in frequency (Fig. 5).

\section{Papers in this special issue of Diversity and Distributions as a sample of the current research directions and focus in invasion ecology}

The special issue of Diversity and Distributions (Volume 14:2) on 'Fifty years of invasion ecology - the legacy of Charles Elton' contains 28 papers that address a very wide range of biogeographic/ecological topics relating to biological invasions. These papers were not solicited, and represent the standard fare of accepted papers on invasion ecology in the journal, similar in scope and cross-section to previous volumes. Given the focus of the journal (conservation biogeography), purely applied topics 
and those relating to economic and sociological issues are not considered for publication (Richardson, 2005). We consider the collected papers to form a reasonably representative set of studies, in terms of taxa, geographical regions and issues in invasion ecology. It is useful to use this sample as a basis for discussion on current research directions in relation to Elton's legacy.

Firstly, only 4 of the papers (14\%) in the special issue cite Elton's (1958) book (Ashton \& Lerdau, 2008; Gordon et al., 2008; Ricklefs et al., 2008; Walter \& Levin, 2008). If we consider the coverage of topics addressed in the special issue and compare this with the major topics referred to in papers that have cited Elton's book since its publication (Fig. 4), some interesting patterns emerge. The largest number of papers fall into our category of 'dispersal, spread and elimination of barriers' (Audzijonyte et al., 2008; Hufbauer \& Sforza, 2008; Kobelt \& Nentwig, 2008; Nielsen et al., 2008; Piel et al., 2008; Provan et al., 2008 ; Westcott et al., 2008). Five papers dealt with issues pertaining to the impacts of biological invasions (Lach, 2008; Leprieur et al., 2008; Ricciardi \& Kipp, 2008; Sims et al., 2008; Walter \& Levin, 2008). The role of disturbance (Chabrerie et al., 2008; Piola \& Johnston, 2008; Walter \& Levin, 2008), 'range expansions, population outbreaks and ecological explosions' (Pyšek et al., 2008; Tolley et al., 2008), enemy release (Ashton \& Lerdau, 2008; Ebeling et al., 2008), the invasibility of islands (Walter \& Levin, 2008), and resource utilization (Hastwell et al., 2008) were also covered. Seven of the broad categories in Fig. 4 are not covered, at least as a major focus, in the special issue. Importantly, nearly a third of papers in the special issue are on topics that were not addressed at all by Elton. These include: detailed studies of the determinants of invasibility (Kilroy et al., 2008; Truscott et al., 2008), multi-scale comparisons of biogeographical patterns (Ricklefs et al., 2008), analytical distribution modelling (Real et al., 2008), the role of propagule pressure (Mikheyev et al., 2008), and post-introduction evolution, in particular the role of hybridization (Ayres et al., 2008). Two papers deal with issues pertaining to risk assessment (Crossman \& Bass, 2008; Gordon et al., 2008), and one presents an analysis of transitions between categories of alien species (Caley et al., 2008).

What can we say about current focus areas in invasion ecology (with reference to, but not considering only, our sample of papers in this special issue) if we consider the field of biological invasions as defined by Charles Elton half a century ago? Clearly, several fundamental topics have emerged as important focus areas of research in biological invasions post-Elton. The crucial roles of facilitation, dispersal dynamics (including long-distance dispersal), propagule pressure, phenotypic plasticity and rapid evolution, which are now recognized as vital determinants of invasiveness and invasibility (Daehler, 2006; Richardson \& Pyšek, 2006), were not discussed by Elton (Richardson \& Pyšek, 2007). Although Elton (1958) mentioned dispersal in various ways, modern studies have revolutionized the study of dispersal, for instance through the conceptualization, description and parameterization of invasion pathways (Ruiz \& Carlton, 2003; Hulme et al., 2008). Several papers in this issue are indicative of such advances (Kobelt \& Nentwig, 2008; Piel et al., 2008). The realization that rare, long-distance dispersal (LDD) events are crucial in invasions (Trakhtenbrot et al., 2005), is confirmed by the attention given to LDD in the special issue (Nielsen et al., 2008; Pyšek et al., 2008; Tolley et al., 2008; Westcott et al., 2008).

Some issues not covered by Elton (1958) that now enjoy considerable attention owe their emergence simply to the radical escalation in the number of taxa invading and the overall extent of invasions worldwide and thus increasing awareness of actual and potential threats to biodiversity and ecosystem functioning. For example, Caley et al.'s (2008) analysis of naturalization rates of introduced plants for Australia, drawing on concepts developed by Mark Williamson in his Tens Rule (Williamson, 1993; Williamson \& Fitter, 1996), is only useful now that hundreds of species, introduced decades ago, are considered potentially invasive. Similarly, the recent upsurge in interest in risk assessment as a facet of strategies to manage invasions (Crossman \& Bass, 2008; Gordon et al., 2008) mirrors the widespread adoption of risk analysis and management in all spheres of human endeavour, including economics, engineering and human health (Burgman, 2005). As a pervasive environmental stressor, with management options that demand value-laden decisions from numerous role players, biological invasions are an important field for the application of risk assessment (Maguire, 2004). Other obvious reasons for the emergence of new fields of research in areas not discussed by Elton (1958) are the current widespread availability of comprehensive data sets and important technological innovations that have paved the way for insights that could not have been foreseen 50 years ago. Radical advances in computing power and statistical methods and new modelling approaches and tools such as geographic information systems have made possible multi-scale analyses that have revolutionized the study of biogeography (see Crossman \& Bass, 2008; Nielsen et al., 2008; Pyšek et al., 2008; Ricklefs et al., 2008, for examples using these techniques in the current special issue). Rapid advances in techniques for modelling species distributions have been widely applied, in numerous ways, in invasion ecology (e.g. Nielsen et al., 2008). Recent advances in molecular ecology, too, have opened doors to insights on aspects of invasion ecology that Elton would never have dreamt of, for example as a tool for reconstructing the routes (e.g. Provan et al., 2008) and elucidating the mechanisms (e.g. Hufbauer \& Sforza, 2008) of invasions. The collection of papers on spread and invasion histories of alien species in this issue neatly illustrates the development of methodological tools that were not available in Elton's time. What he documented (rather clearly) using hand-drawn maps, is now reconstructed using molecular methods (Audzijonyte et al., 2008; Hufbauer \& Sforza, 2008; Provan et al., 2008; Tolley et al., 2008) or deconstructed using modern mathematics and modelling techniques (e.g. Nielsen et al., 2008).

Experimental studies are increasingly being applied to test key theories and assumptions in invasion ecology (e.g. Ashton \& Lerdau, 2008; Hastwell et al., 2008; Piola \& Johnston, 2008). Some of the studies in this issue (Ebeling et al., 2008; Westcott et al., 2008) could have been conducted in Elton's time, i.e. they utilize no particular modern technologies, but are framed within 
theoretical paradigms that post-date Elton. The increasing availability of data also permits the computation of better measures of propagule pressure; numerous recent studies attest to the crucial role of this factor in driving invasions (e.g. Mikheyev et al., 2008).

Despite a huge increase in the number of taxa studied and regions where studies are carried out, taxonomical and geographical biases are clearly evident in published research on biological invasions (Pyšek et al., 2008). Similar patterns are evident in the papers in this special issue. More than half of the papers (15) in the special issue address invasive plants, followed by arthropods (4 papers; 2 dealing with ants, one with spiders, and one with many groups). Crustaceans, fishes, frogs, mammals and marine algae are all represented by one paper. Five papers deal with multi-taxon groups: diatoms, freshwater organisms, invertebrates, macroinvertebrates and vertebrates. European studies are represented by 12 papers, Australasia by 6, North America by 4, Africa by 3, and Asia and the Pacific Islands by one each. One study presented a global overview.

Interestingly, only nine of the 49 most-studied taxa identified in a comprehensive review of published work on invasions (with 10 or more case studies on the Web of Science; P. Pyšek, D.M. Richardson et al., unpubl. data) were mentioned by Elton. For plants, these are Lantana camara (lantana) and Spartina alterniflora (smooth cordgrass); for insects Adelges tsugae (hemlock woolly adelgid), Aedes albopictus (Asian tiger mosquito), Linepithema humile (Argentine ant), Lymantria dispar (gypsy moth) and Solenopsis invicta (red imported fire ant); for crustaceans Eriocheir sinensis (Chinese mitten crab); and for mammals Rattus rattus (black rat). That Elton did not mention current poster-child examples of invaders like Dreissena polymorpha (zebra mussel), Centaurea maculosa (spotted knapweed), Caulerpa taxifolia (the 'killer alga'), Bromus tectorum (cheatgrass), Heracleum mantegazzianum (giant hogweed), Bufo marinus (cane toad) and Carpobrotus edulis (common Hottentot fig) (P. Pyšek, D.M. Richardson et al., unpubl. data) is indicative of the huge changes in the status of key invaders around the world over the last 50 years. That modern researchers still cite Elton's book so often, despite the radical changes in the taxa under consideration, and the range of associated problems and challenges for managers, is further evidence of the enduring value of Elton's synthesis and roadmap for research.

What are main challenges for invasion ecology? It is beyond the scope of this short editorial to do justice to this question, but we offer a few subjective ideas on profitable avenues for research in invasion ecology.

- We must capitalize on advances in molecular technology to unlock secrets of the biology of invasive species, for example relating to dispersal ecology (notably the importance of rare, long-distance dispersal) and to aid in reconstructing the history of invasions.

- Despite considerable advances in the development of sophisticated species distribution models, the application of such models to invasive alien species remains problematical. This is because most invasive species have had insufficient time in their new ranges to sample all potentially invasible habitats. This means that correlations between current range and environmental factors do not necessarily provide an accurate definition of potential range. Using localities in the native range or other regions where the species has become invasive is also problematical in the absence of information on the genetic makeup of introduced populations. Research is required to facilitate the quantification of levels of uncertainty when using such models. There is also an urgent need for more high-quality data sets to improve our ability to model and predict distributions.

- Increasing numbers of studies invoke propagule pressure as a (or the) fundamental driver of invasions. Many use indirect proxies of propagule pressure, since direct measures of numbers of introduced propagules are difficult or impossible to generate. Some standardization on optimum proxies in this regard would be helpful and could facilitate more robust generalizations on the relative importance of this factor. Care needs to be taken to account for confounding factors and biases in comparative analyses of habitat invasibility and species invasiveness (see e.g. Colautti et al., 2006; Pyšek et al., 2005; Chytrý et al., 2008). Understanding propagule pressure is the new frontier in invasion ecology (Richardson, 2004).

- The literature on invasion ecology contains a growing number of theories and generalizations, with much duplication, redundancy and reinventing of the wheel. There is a need to distil the fundamental issues from the different theories, while realizing that invasions are context specific (Cadotte et al., 2006; Richardson \& Pyšek, 2006).

- Invasion ecology needs to continue building bridges with other disciplines, following the course charted by Elton. Key areas where improved links with invasion ecology would be mutually beneficial include conservation biology/biogeography, global change biology, restoration ecology, weed science, resource economics, human geography and policy studies.

- It is generally accepted that global change will exacerbate problems with biological invasions. Much more research is required to understand the mechanisms that could potentially facilitating responses of key invasive species to elevated $\mathrm{CO}_{2}$ and other elements of global change. Since influential changes are sure to involve extremely complex multi-scale interactions, radically improved modelling frameworks to accommodate robust predictions are urgently needed.

- We concur with Hulme (2003) who bemoaned the lack of effective translation of academically gratifying research results in many areas of invasion ecology to management. Theoretical advances need to be translated into improved management, including objective means for conflict resolution. More research in invasion ecology needs to engage sociologists, human geographers, and others in positions to facilitate effective transfer of key results to implementation (Richardson et al., 2008).

\section{ACKNOWLEDGMENTS}

We thank Zuzana Sixtová for preparing data for the citation analysis and Ivan Ostrý for logistic support. D.M.R. acknowledges support from the DST-NRF Centre of Excellence for Invasion Biology and the Hans Sigrist Foundation. P.P. was supported by 
institutional long-term research plans no. AV0Z60050516 from the Academy of Sciences of the Czech Republic, no. 0021620828 from MŠMT $\breve{C}$, and by Biodiversity Research Centre, grant LC 06073 from MŠMT ČR. Marc Cadotte and Hugh MacIsaac provided useful comments on an early draft.

\section{REFERENCES}

Ashton, I.W. \& Lerdau, M.T. (2008) Tolerance to herbivory, and not resistance, may explain differential success of invasive, naturalized, and native North American temperate vines. Diversity and Distributions, 14, 169-178.

Audzijonyte, A., Wittmann, K.J. \& Väinölä, R. (2008) Tracing recent invasions of the Ponto-Caspian mysid shrimp Hemimysis anomala across Europe and to North America with mitochondrial DNA. Diversity and Distributions, 14, 179-186.

Ayres, D.R., Zaremba, K., Sloop, C.M. \& Strong, D.R. (2008) Sexual reproduction of cordgrass hybrids (Spartina foliosa $\mathrm{x}$ alterniflora) invading tidal marshes in San Francisco Bay. Diversity and Distributions, 14, 187-195.

Burgman, M. (2005) Risks and decisions for conservation and environmental management. Cambridge University Press, Cambridge.

Cadotte, M.W. (2006) Darwin to Elton: early ecology and the problem of invasive species. Conceptual ecology and invasion biology (ed. by M.W. Cadotte, S.M. McMahon and T. Fukami), pp. 15-33. Springer, Berlin.

Cadotte, M.W., McMahon, S.M. \& Fukami, T. (eds) (2006) Conceptual ecology and invasion biology. Springer, Berlin.

Caley, P., Groves, R.H. \& Barker, R. (2008) Estimating the invasion success of introduced plants. Diversity and Distributions 14, 196-203.

Carlton, J.T. \& Geller, J.B. (1993) Ecological roulette: the global transport of nonindigenous marine organisms. Science 261, 78-82.

Chabrerie, O., Verheyen, K., Saguez, R. \& Decocq, G. (2008) Disentangling relationships between habitat conditions, disturbance history, plant diversity, and American black cherry (Prunus serotina Ehrh.) invasion in a European temperate forest. Diversity and Distributions, 14, 204-212.

Chytrý, M., Jarošík, V., Pyšek, P., Hájek, O., Knollová, I., Tichý, L. \& Danihelka, J. (2008) Separating habitat invasibility by alien plants from the actual level of invasion. Ecology, in press.

Colautti, R.I., Grigorovich, I.A. \& MacIsaac, H.J. (2006) Propagule pressure: a null model for biological invasions. Biological Invasions, 8, 1023-1037.

Crossman, N.D. \& Bass, D.A. (2008) Application of common predictive habitat techniques for post-border weed risk management. Diversity and Distributions, 14, 213-224.

D’Antonio, C.M. \& Vitousek, P.M. (1992) Biological invasions by exotic grasses, the grass fire cycle, and global change. Annual Review of Ecology and Systematics, 23, 63-87.

Daehler, C.C. (2006) Invasibility of tropical islands by introduced plants: partitioning the role of isolation and propagule pressure. Preslia, 78, 389-404.
Davis, M. (2006) Invasion biology 1958-2005: the pursuit of science and conservation. Conceptual ecology and invasion biology (ed. by M.W. Cadotte, S.M. McMahon \& T. Fukami), pp. 35-64. Springer, Dordrecht.

Drake, J.A., Mooney, H.A., Di Castri, F., Groves, R.H., Kruger, F.J., Rejmánek, M. \& Williamson, M. (eds) (1989) Biological invasions: a global perspective. J. Wiley, Chichester.

Ebeling, S.K., Hensen, I., Auge, H. (2008) The invasive shrub Buddleja davidii performs better in its introduced range. Diversity and Distributions, 14, 225-233.

Elton, C.S. (1958) The ecology of invasions by animals and plants. Methuen, London.

Gordon, D.R., Onderdonk, D.A., Fox, A.M. \& Stocker, R.K. (2008) Consistent accuracy of the Australian Weed Risk Assessment system across varied geographies. Diversity and Distributions, 14, 234-242.

Hastwell, G.T., Daniel, A.J. \& Vivian-Smith, G. (2008) Predicting invasiveness in exotic species: do subtropical native and invasive exotic aquatic plants differ in their growth responses to macronutrients? Diversity and Distributions, 14, 243-251.

Hufbauer, R.A. \& Sforza, R. (2008) Multiple introductions of two invasive Centaurea taxa inferred from cpDNA haplotypes. Diversity and Distributions, 14, 252-261.

Hulme, P.E. (2003) Biological invasions: winning the science battles but losing the conservation war? Oryx, 37, 178-193.

Hulme, P.E., Bacher, S., Kenis, M., Klotz, S., Kühn, I., Minchin, D., Nentwig, W., Olenin, S., Panov, V., Pergl, J., Pyšek, P., Roque, A., Sol, D., Solarz, W. \& Vila, M. (2008) Grasping at the routes of biological invasions: a framework for integrating pathways into policy. Journal of Applied Ecology, doi: 10.1111/ j.1365-2664.2007.01442.x.

Kilroy, C., Snelder, T.H., Floerl, O., Vieglais, C.V. \& Dey, K.L. (2008) A rapid technique for assessing the suitability of areas for invasive species applied to New Zealand's rivers. Diversity and Distributions, 14, 262-272.

Kobelt, M. \& Nentwig, W. (2008) Alien spider introductions to Europe supported by global trade. Diversity and Distributions, 14, 273-280.

Lach, L. (2008) Argentine ants displace floral arthropods in a biodiversity hotspot. Diversity and Distributions, 14, 281-290.

Leprieur, F., Beauchard, O., Hugueny, B. Grenouillet, G. \& Brosse, S. (2008) Null model of biotic homogenization: a test with the European freshwater fish fauna. Diversity and Distributions, 14, 291-300.

Mack, R.N., Simberloff, D., Lonsdale, W.M., Evans, H., Clout, M. \& Bazzaz, F.A. (2000) Biotic invasions: causes, epidemiology, global consequences, and control. Ecological Applications, 10, 689-710.

Maguire, L.A. (2004) What can decision analysis do for invasive species management? Risk Analysis, 24, 859-868.

Mikheyev, A.S., Tchingnoumba, L., Henderson, A. \& Alonso, A. (2008) Effect of propagule pressure on the establishment and spread of the little fire ant Wasmannia auropunctata in a Gabonese oilfield. Diversity and Distributions, 14, 301-306.

Nielsen, C., Hartvig, P. \& Kollmann, J. (2008) Predicting the distribution of the invasive alien Heracleum mantegazzianum 
at two different spatial scales. Diversity and Distributions, 14, 307-317.

Piel, F., Gilbert, M., De Cannière, C. \& Grégoire, J.-C. (2008) Coniferous round wood imports from Russia and Baltic countries to Belgium. A pathway analysis for assessing risks of exotic pest insect introductions. Diversity and Distributions, 14, 318-328.

Piola, R.F. \& Johnston, E.L. (2008) Pollution reduces native diversity and increases invader dominance in marine hard-substrate communities. Diversity and Distributions, 14, 329-342.

Provan, J., Booth, D., Todd, N.P., Beatty, G.E. \& Maggs, C.A. (2008) Tracking biological invasions in space and time: elucidating the invasive history of the green alga Codium fragile using old DNA. Diversity and Distributions, 14, 343-354.

Pyšek, P., Jarošík, V., Chytrý, M., Kropáč, Z., Tichý, L. \& Wild, J. (2005) Alien plants in temperate weed communities: Prehistoric and recent invaders occupy different habitats. Ecology, 86, 772-785.

Pyšek, P., Jarošík, V., Müllerová, J., Pergl, J. \& Wild, J. (2008) Comparing the rate of invasion by Heracleum mantegazzianum at continental, regional, and local scales. Diversity and Distributions, 14, 355-363.

Pyšek, P., Richardson, D.M. \& Jarošík, V. (2006) Who cites who in the invasion zoo: insights from an analysis of the most highly cited papers in invasion ecology. Preslia 78, 437-468.

Real, R., Márquez, A.L., Estrada, A., Muñoz, A.R. \& Vargas, J.M. (2008) Modelling chorotypes of invasive vertebrates in mainland Spain. Diversity and Distributions, 14, 364-373.

Ricciardi, A. \& Kipp, R. (2008) Predicting the number of ecologically harmful exotic species in an aquatic system. Diversity and Distributions, 14, 374-380.

Richardson, D.M. (2004) Plant invasion ecology - dispatches from the front line. Diversity and Distributions, 10, 315-319.

Richardson, D.M. (2005) Diversity, distributions and conservation biogeography. Diversity and Distributions, 11, 1-2.

Richardson, D.M. (2006) Pinus: a model group for unlocking the secrets of alien plant invasions. Preslia, 78, 375-388.

Richardson, D.M. \& Pyšek, P. (2006) Plant invasions: merging the concepts of species invasiveness and community invasibility.

Progress in Physical Geography, 30, 409-431.

Richardson, D.M. \& Pyšek, P. (2007) Classics in physical geography revisited: Elton, C.S. 1958. The Ecology of invasions by animals and plants. Progress in Physical Geography, 31, 659666.

Richardson, D.M. \& van Wilgen, B.W. (2004) Invasive alien plants in South Africa: how well do we understand the ecological impacts? South African Journal of Science, 100, 45-52.

Richardson, D.M., Pyšek, P., Simberloff, D., Rejmánek, M. \& Mader, A.D. (2008) Biological invasions - the widening debate. Progress in Human Geography, in press.

Ricklefs, R.E., Guo, Q. \& Qian, H. (2008) Growth form and distribution of introduced plants in their native and non- native ranges in Eastern Asia and North America. Diversity and Distributions, 14, 381-386.

Ruiz, G. \& Carlton, J. (eds) (2003) Invasive species: vectors and management strategies. Island Press, Washington, DC.

Sims, V., Evans, K.L., Newson, S.E., Tratalos, J. \& Gaston, K.J. (2008) Avian assemblage structure and domestic cat densities in urban environments. Diversity and Distributions, 14, 387399.

Tolley, K.A., Davies, S.J. \& Chown, S.L. (2008) Deconstructing a controversial local range expansion: conservation biogeography of the painted reed frog (Hyperolius marmoratus) in South Africa. Diversity and Distributions, 14, 400-411.

Trakhtenbrot, A., Nathan, R., Perry, G. \& Richardson, D.M. (2005) The importance of long-distance dispersal in biodiversity conservation. Diversity and Distributions, 11, 173-181.

Truscott, A.-M., Palmer, S.C.F., Soulsby, C. \& Hulme, P.E. (2008) Assessing the vulnerability of riparian vegetation to invasion by Mimulus guttatus: relative importance of biotic and abiotic variables in determining species occurrence and abundance. Diversity and Distributions, 14, 412-421.

Walter, S.H. \& Levin, G.A. (2008) Feral sheep on Socorro Island: facilitators of alien plant colonization and ecosystem decay. Diversity and Distributions, 14, 422-431.

Westcott, D.A., Setter, M.A., Bradford, M.G., McKeown, A. \& Setter, S. (2008) Cassowary dispersal of the invasive pond apple in a tropical rainforest: the contribution of subordinate dispersal modes in invasion. Diversity and Distributions, 14, 432-439.

Williamson, M. (1993) Invaders, weeds and the risk from genetically manipulated organisms. Experientia, 49, 219224.

Williamson, M. \& Fitter. A. (1996) The varying success of invaders. Ecology, 77, 1661-1666.

\section{SUPPLEMENTARY MATERIAL}

The following supplementary material is available for this article:

Appendix S1 References to the topics dealt with by Charles Elton in his book The ecology of invasions by animals and plants (Elton, 1958), grouped by decade between 1960 and 2006. Based on 20 randomly selected papers for each decade (see text for details).

This material is available as part of the online article from: http://www.blackwell-synergy.com/doi/abs/10.1111/j.14724642.2008.00464.x

(This link will take you to the article abstract)

Please note: Blackwell Publishing are not responsible for the content or functionality of any supplementary materials supplied by the authors. Any queries (other than missing material) should be directed to the corresponding author for the article. 